\title{
SERUM TNF- RELATED WEAK INDUCER OF APOPTOSIS (TWEAK), TNF- RELATED APOPTOSIS-INDUCING LIGAND (TRAIL) LEVELS IN PATIENTS WITH BIPOLAR DEPRESSION, MAJOR DEPRESSION AND A HEALTHY CONTROL GROUP
}

\author{
Hasan Karada $\breve{g}^{1}$, Görkem Saygılı', Rabia Yüksel ${ }^{3}$, Miraç Barış Usta ${ }^{4}$, \\ Canan Topçuoğlu ${ }^{5}$ \& Gamze Erzin ${ }^{1}$ \\ ${ }^{l}$ University of Health Sciences, Dışkapı Training and Research Hospital, Psychiatry Department, Ankara, Turkey \\ ${ }^{2}$ Cognitive Science and Artifical Intelligence Department Tilburg University, Tilburg, Netherlands \\ ${ }^{3}$ Ankara City Hospital, Psychiatry Department, Ankara, Turkey \\ ${ }^{4}$ Ondokuz Mayis University, Child and Adolescent Psychiatry and Mental Health Department, Ankara, Turkey \\ ${ }^{5}$ Ankara City Hospital, Biochemistry Department, Ankara, Turkey
}

received: 10.1.2021;

revised: 25.5.2021;

accepted: 6.6 .2021

\section{SUMMARY}

Background: A low-grade inflammation is presumed to be related to the etiopathogenesis of major depressive disorder (MDD) and bipolar disorder. Tumor necrosis factor (TNF) superfamily members have roles in the pathogenesis of neuropsychiatric disorders because of the relationship with inflammation and neurogenesis. The aim of this study was to investigate the serum TNFrelated weak inducer of apoptosis (TWEAK) and TNF-related apoptosis-inducing ligand (TRAIL) levels in patients with bipolar depression (BD), MDD and a healthy control (HC) group to determine any differences between MDD and BD in terms of inflammation biomarkers.

Subjects and methods: After a 12-hour overnight fast, 5 milliliter $(\mathrm{mL})$ samples of fasting blood were obtained from the participants. The TWEAK and TRAIL plasma levels were calculated using ELISA kits.

Results: The TWEAK levels were found to be higher in the BD group than in the HC group $(p=0.03)$. No statistically significant differences were determined between the $B D$ vs $M D D$ and $M D D v s$ HC groups $(p=0.17, p=0.37$, respectively). There were no statistically significant differences between the three groups ( $B D$ vs HC; BD vs MDD; MDD vs HC) in terms of TRAIL levels $(p=0.21)$.

Conclusion: To the best of our knowledge, this study is the first to have explored TWEAK levels in patients with BD. The higher $T W E A K$ levels in BD than in the control group is compatible with the inflammation hypothesis of BD. Limitations of the study were the differences in medications of the patient groups and that it was a cross-sectional study. There is a need for further longitudinal studies with larger sample size and medication-free patients.

Key words: major depressive disorder - bipolar disorder - tumor necrosis factor - inflammation - neurogenesis

$$
* * * * *
$$

\section{INTRODUCTION}

Bipolar Disorder has a course of recurrent manic and depressive episodes, characterized by fluctuations in mood states and energy levels (Grande et al. 2016). Recent studies have shown that inflammatory abnormalities may have a role in the pathophysiology of this condition, just as many studies have shown elevated levels of proinflammatory cytokines in patients with bipolar disorder (Muneer 2016, Bai et al. 2014, Kim et al. 2007). Of these cytokines, the most consistent evidence has been of elevated levels of tumor necrosis factor $\alpha$ (TNF- $\alpha$ ) (Hope et al. 2011, Cunha et al. 2008, Drexhage et al. 2010, Goldstein et al. 2009). As recent studies have shown associations between inflammatory markers and affective indications in patients with bipolar disorder (Hamdani et al. 2012), such as platelet-to-lymphocyte ratio was regard as an independent predictor of manic episode (Fusar-Poli et al. 2021). This evidence has shifted attention to the TNF super- family (TNFSF) in the pathophysiology of bipolar disorder (Barbosa et al. 2017).

Increased pro-inflammatory agents, such as TNF, may exemplify low-grade inflammation in major depressive disorder (MDD), which is similar to bipolar disorder (Kopschina et al. 2017). According to the inflammation hypothesis, patients with MDD have increased levels of pro-inflammatory cytokines, such as TNF- $\alpha$ (Schmidt et al. 2019). Although there are similarities between these disorders in terms of the inflammation process, there are also differences (Brunoni et al. 2020).

TNF-related weak inducer of apoptosis (TWEAK) is a cytokine that belongs to TNFSF and has been reported in many tissues including the brain (Kopschina et al. 2017). TWEAK has also been shown to have long range effects as a secreted cytokine and to be able to induce interleukin-8 (IL-8), IL-12 and interferon-gamma synthesis (Chicheportiche et al. 1997, Maecker et al. 2005). TWEAK levels have a positive 
correlation with TNF-alpha $(\alpha)$ plasma levels (Barbosa et al. 2017). Recent studies have shown TWEAK and its cell surface receptor fibroblast growth factorinducible 14 (Fn14) expressed in astrocytes, microglia and neurons with a subsequent increase in the permeability of the blood-brain barrier (Yepes 2007). Monocytes/macrophages release TWEAK, and TWEAK and its receptor indicate inflammatory tissue injury in multiple sclerosis (Campbell et al. 2004, Serafini et al. 2008).

TNF-related apoptosis-inducing ligand (TRAIL) is a member of TNFSF and an apoptosis inducer (JouanLanhouet et al. 2012), which has also been shown to have immunosuppressive and immunoregulatory effects (Falschlehner et al. 2009). The TRAIL receptor system also plays a role in various autoimmune diseases. TRAIL blockage has been reported to cause a higher degree of inflammation in the central nervous system in an experimental multiple sclerosis model (Cretney et al. 2005). In another study with an experimental diabetes model, TRAIL blockage increased the degree of autoimmune inflammation in both pancreatic island cells and salivary glands (Lamhamedi-Cherradi et al. 2003). Furthermore, TRAIL may be important in adjusting the outcomes of immune diseases, based on immune regulation effects (Lünemann et al. 2002). In previous studies, TWEAK and TRAIL levels were examined in patients with bipolar disorder in a manic and depressive episode and patients with schizophrenia (Yirun et al. 2017, Yaylac1 et al. 2015).

Therefore, in the light of the findings from previous studies, due to the consistent association between TNF- $\alpha$ and bipolar disorder and major depressive disorder, TWEAK and TRAIL levels have been found worthy of the investigation for these diseases.

This study investigated whether TWEAK and TRAIL might be helpful in explaining underlying biological differences such as inflammation processes in MDD and bipolar disorder depressive episode (BD). The aim of our study was to evaluate levels of TWEAK and TRAIL in patients with BD and MDD compared to a healthy control group to determine whether or not there were any differences between MDD and BD in terms of TWEAK and TRAIL levels.

\section{SUBJECTS AND METHODS}

\section{Method}

The study consecutively enrolled 31 patients with BD and 25 patients with MDD who were being followed up at the University of Health Science Ankara Numune Training and Research Hospital. The diagnosis was confirmed by two experienced clinicians according to the Diagnostic and Statistical Manual of Mental Disorders, 5th edition. Patients with bipolar depression or major depression between the ages of 18-65 who applied to the outpatient clinic of the hospital were included in the study. The control group comprised healthy individuals who were applying to other departments of the hospital with no psychiatric or neurological disease and was age and gender-matched to the patient groups. Patients were excluded from the study if they had any chronic inflammatory diseases, hypertension, obesity, autoimmune disorders, mental retardation, pregnancy, cardiovascular disease, malignancy, metabolic syndrome, diabetes mellitus, alcohol or substance abuse, or use of immunosuppressive agents.

Approval for the study was granted by the Ethics Committee of the University of Health Science Ankara Numune Training and Research Hospital (number: E171629; date: 22.11.2017). Informed consent was obtained from all the study participants.

\section{Blood Sampling}

After a 12-hour overnight fast, five milliliter $(\mathrm{mL})$ samples of fasting blood were obtained from the participants. Blood samples were isolated from sera within 30 to 60 minutes of collection and stored at $80^{\circ} \mathrm{C}$ until required for analysis. On the same day, the Hamilton Depression Rating Scale (HAM-D) was applied to each patient to evaluate the severity of depression in the patients with depression. Turkish validity and reliability studies of this scale were made by Akdemir et al. (Hamilton 1960, Akdemir et al. 1996).

\section{TWEAK and TRAIL Analysis}

Enzyme-linked immunosorbent assay (ELISA) kits (Invitrogen, Thermo Fisher Scientific Inc. Bender MedSystems GmbH Campus Vienna Biocenter 2, 1030, Austria. REF No: BMS2006INST, LOT No: 150748041) were used to determine the levels of serum TWEAK. The measurement range was 46.88$3000 \mathrm{pg} / \mathrm{mL}$. Sensitivity was $40 \mathrm{pg} / \mathrm{mL}$ and the inwork $\mathrm{CV} \%$ values were $<10 \%$, and $\mathrm{CV} \%$ values in between the runs were $<12 \%$.

Enzyme-linked immunosorbent assay (ELISA) kits (Invitrogen, Thermo Fisher Scientific Inc. Bender MedSystems GmbH Campus Vienna Biocenter 2, 1030, Austria. REF No: BMS2004, LOT No: 166991018) were used to determine levels of serum TRAIL. The measurement range was $15.6-1000 \mathrm{pg} / \mathrm{mL}$. Sensitivity was $5 \mathrm{pg} / \mathrm{mL}$ and the in-work $\mathrm{CV} \%$ values were $<6.5 \%$, and $\mathrm{CV} \%$ values in between the runs were $<7.7 \%$.

\section{Statistical Analysis}

SPSS version 21.0 software (SPSS, Chicago, IL, USA) was used for statistical analysis. The Kolmogorov-Smirnov test was used to assess conformity of the data to normal distribution. The Chi-square and Kruskal-Wallis tests were used to compare grouped data and numerical data respectively in the three groups. To 
determine two-way comparisons between groups the Mann-Whitney $U$ test with Bonferroni correction was applied. The level of significance was set at $p=0.05 / 3=0.017$ for the Mann-Whitney $U$ test with Bonferroni correction and at $p=0.05$ for all other comparisons.

\section{RESULTS}

Evaluation was made of 31 patients with BD, 25 patients with MDD and $32 \mathrm{HC}$ subjects. There were no differences between the three groups in terms of age and gender ( $p=0.577, p=0.762$, respectively). There were no statistically significant differences between BD and MDD in terms of HAM-D rating score and duration of disease ( $p=0.912, p=0.785$, respectively) (Table 1$)$.

TWEAK levels were found to be higher in the BD group than in the HC group $(p=0.026)$. There were no statistically significant differences between the BD vs
MDD and MDD vs HC groups ( $\mathrm{p}=0.171, \mathrm{p}=0.368$, respectively). There were no statistically significant differences between the three groups (BD vs HC; BD vs MDD; MDD vs HC) in terms of TRAIL levels $(\mathrm{p}=0.206)$ (Table 2).

No statistically significant differences were determined between the three groups (BD vs $\mathrm{HC}$; $\mathrm{BD}$ vs MDD; MDD vs HC) in terms of C-reactive protein (CRP) levels ( $\mathrm{p}=0.21, \mathrm{p}=0.45, \mathrm{p}=0.74$, respectively).

\section{HAM-D correlations}

There was no correlation between TWEAK levels, TRAIL levels, and HAM- D total score in patients with $\mathrm{BD}$ (rho: $0.14, \mathrm{p}=0.31$; rho: $-0.14, \mathrm{p}=0.31$, respectively).

There was no correlation between TWEAK levels, TRAIL levels, and HAM- D total score in patients with MDD (rho: $0.02, \mathrm{p}=0.93$; rho: $-0.13, \mathrm{p}=0.54$, respectively).

Table 1. Comparison of the sociodemographic and clinical data between BD, MDD and HC groups

\begin{tabular}{|c|c|c|c|c|c|}
\hline Study Parameter & $\begin{array}{l}\text { BD group } \\
(\mathrm{n}: 31)\end{array}$ & $\begin{array}{l}\text { MDD group } \\
(\mathrm{n}: 25)\end{array}$ & $\begin{array}{l}\text { HC group } \\
\text { (n: } 32)\end{array}$ & Test statistics & $\mathrm{p}$ \\
\hline Age (years) & $37.8 \pm 10.4$ & $41.4 \pm 13.6$ & $40.0 \pm 11.46$ & $F: 0.554$ & 0.577 \\
\hline Gender (female) & $58.1 \%$ & $68.2 \%$ & $58.6 \%$ & $\chi^{2}: 0.544$ & 0.762 \\
\hline $\begin{array}{l}\text { Hamilton Depression } \\
\text { Rating Score }\end{array}$ & $\begin{array}{c}\text { Median } 26 \\
(\min 20-\max 58)\end{array}$ & $\begin{array}{c}\text { Median } 27 \\
(\min 19-\max 53)\end{array}$ & - & Z: 0.108 & 0.912 \\
\hline $\begin{array}{l}\text { Duration of disorder } \\
\text { (years) }\end{array}$ & $\begin{array}{c}\text { Median } 5 \\
(\min 2-\max 18)\end{array}$ & $\begin{array}{c}\text { Median } 4 \\
(\min 4-\max 22)\end{array}$ & - & $Z: 0.273$ & 0.785 \\
\hline $\begin{array}{l}\text { Number of } \\
\text { hospitalizations }\end{array}$ & $\begin{array}{c}\text { Median } 2 \\
(\min 0-\max 8)\end{array}$ & - & - & - & - \\
\hline Depressive episodes & $\begin{array}{c}\text { Median } 2 \\
(\min 1-\max 6)\end{array}$ & $\begin{array}{c}\text { Median } 2 \\
(\min 1-\max 3)\end{array}$ & - & $Z: 0.731$ & 0.482 \\
\hline Manic episodes & $\begin{array}{c}\text { Median } 1 \\
(\min 1-\max 5)\end{array}$ & - & - & - & - \\
\hline
\end{tabular}

Note: ANOVA, Chi-Square and Mann-Whitney U tests used for analysis; BD: bipolar depression;

MDD: major depressive disorder; HC: healthy control group

Table 2. Comparison of TWEAK, TRAIL levels and TWEAK/TRAIL ratio between the BD, MDD and HC groups

\begin{tabular}{|c|c|c|c|c|c|c|c|c|c|}
\hline \multicolumn{2}{|c|}{ Study Parameter } & $\begin{array}{l}\text { BD group } \\
(\mathrm{n}: 31)\end{array}$ & $\begin{array}{l}\text { MDD group } \\
\text { (n: } 25)\end{array}$ & $\begin{array}{l}\text { HC group } \\
\text { (n: } 32)\end{array}$ & KW & $\mathrm{p}$ & $\mathrm{p} 1^{*}$ & $\mathrm{p} 2^{*}$ & $\mathrm{p} 3^{*}$ \\
\hline TWEAK & $\begin{array}{l}\text { Ave } \pm \text { SD } \\
\text { Median } \\
\text { (Q1-Q3) }\end{array}$ & $\begin{array}{c}696.81 \pm 461.41 \\
591.10 \\
(472.90-769.20)\end{array}$ & $\begin{array}{c}556.78 \pm 234.04 \\
506.10 \\
(411.15-657.90)\end{array}$ & $\begin{array}{c}502.80 \pm 191.52 \\
502.80 \\
(460.83-646.28)\end{array}$ & 3.867 & 0.15 & 0.03 & 0.17 & 0.37 \\
\hline TRAIL & $\begin{array}{l}\text { Ave } \pm \text { SD } \\
\text { Median } \\
(Q 1-Q 3)\end{array}$ & $\begin{array}{c}31.21 \pm 15.12 \\
26.40 \\
(23.40-31.20)\end{array}$ & $\begin{array}{c}27.23 \pm 13.56 \\
24.60 \\
(21.10-26.40)\end{array}$ & $\begin{array}{c}44.28 \pm 88.94 \\
25.20 \\
(23.40-28.20)\end{array}$ & 3.158 & 0.21 & 0.07 & 0.3 & 0.50 \\
\hline CRP & $\begin{array}{l}\text { Ave } \pm \text { SD } \\
\text { Median } \\
(Q 1-Q 3)\end{array}$ & $\begin{array}{c}3.21 \pm 2.03 \\
2.01 \\
(1.63-4.20)\end{array}$ & $\begin{array}{c}2.73 \pm 1.71 \\
2.16 \\
(1.10-4.10) \\
\end{array}$ & $\begin{array}{c}2.12 \pm 1.93 \\
1.20 \\
(1.00-3.25)\end{array}$ & 4.046 & 0.13 & 0.21 & 0.45 & 0.74 \\
\hline
\end{tabular}

Note: KW: Kruskal-Wallis; SD: Standard Deviation; BD: bipolar depression, MDD: major depressive disorder, $\mathrm{HC}$ : healthy control group; CRP: C reactive protein. " Two-way comparisons of groups. P1: BD vs HC. P2: BD vs MDD. P3: MDD vs HC. Bold values are statistically significant findings.

Power analysis made with GPower 3.1 software (Dusseldorf, Germany). Based on the TWEAK values in Yirün et al. (2017) with $95 \%$ power and alpha: 0.05 it was calculated that the number of patients to be included in each group was at least 10 . 


\section{DISCUSSION}

To the best of our knowledge, this is the first study to have investigated TWEAK and TRAIL levels in patients with BD. The aim of this study was to compare the TWEAK and TRAIL levels between the $\mathrm{BD}, \mathrm{MDD}$ and $\mathrm{HC}$ groups. The principal findings of this study were as follows: (i) the patients with BD had higher TWEAK levels than HC subjects; (ii) TWEAK levels and TRAIL levels had no correlation with HAM-D scores in BD and MDD; (iii) there was no difference between $\mathrm{BD}, \mathrm{MDD}$ and $\mathrm{HC}$ in terms of TRAIL levels.

TWEAK plays a significant role in neuroinflammation by increasing the secretion and expression of many proinflammatory cytokines, such as IL-6, and Prostaglandin E2 (PGE2) (Saas et al 2000, Wiley et al. 2003). It is thought that BD could cause deterioration in inflammatory processes similar to depression. For example, IL-2, which is known to be a proinflammatory cytokine, showed an increase in patients with BD (Bai et al. 2014). There are a few studies in the literature which have investigated TWEAK levels in several neuropsychiatric conditions, although the results are different from those of the current study. In particular, one study which was conducted to investigate the differences in TWEAK levels between schizophrenia and $\mathrm{HC}$ subjects reported no difference between patients with schizophrenia and the healthy control group in terms of TWEAK levels. There was also reported to be no significant correlation between TWEAK level and The Positive and Negative Syndrome Scale (PANSS) score in the same study (Yaylac1 et al. 2015).

A recent study examining TWEAK and TRAIL levels in patients with bipolar disorder in remission periods and manic episodes showed that TWEAK levels were lower in patients with bipolar disorder compared to a control group (Yirun et al. 2017). The result of that study was explained by the deterioration of the TWEAK proinflammatory suppression mechanism in bipolar disorder. Barbosa et al., however, found contrasting results in their studies. When bipolar disorder-1 patients and healthy control subjects were compared, TWEAK levels were found to be increased in bipolar disorder compared to the control group (Barbosa et al. 2017). The results of the current study were consistent with those of the Barbosa et al. study.

However, in the current study there was no evidence of a correlation between TWEAK levels and HAM-D scores in BD and MDD. There were no statistically significant differences between the MDD and $\mathrm{BD}$ groups in respect of age, gender, duration of disease, HAM-D scores, or the levels of TWEAK and TRAIL but the TWEAK levels in BD were found to be higher than those of the HC group. This result could be attributed to the small sample size. Another reason for the lack of difference in TWEAK level between BD and MDD was that characteristics such as body mass index (BMI), waist circumference and dietary habits were not taken into consideration, but these could have affected the inflammatory process. Mood stabilizer drugs and antipsychotic drugs used by bipolar depression patients may have also affected the TWEAK level, as it is known that antidepressant medication can affect levels of inflammation, especially selective serotonin reuptake inhibitors (Vogelzangs et al. 2012, Miller et al. 2009). The MDD group in the current study was also receiving antidepressant therapy. There were no differences in TWEAK levels between the medicated and unmedicated patients with depression and no significant difference was seen between patients who were using valproate sodium and lithium (Kopschina et al. 2017, Yirun et al. 2017).

Neuroinflammation is a major factor contributing to the etiopathogenesis of neurodegeneration and depression (Hurley \& Tizabi 2013). For example, multiple sclerosis (MS) is thought to be a neurodegenerative disorder. Both MS and depression are thought to have impaired neurodegenerative and inflammatory processes. In a previous study of MS patients, the TWEAK level was found to be higher than that of healthy control subjects and the high level of soluble serum TWEAK was associated with neuroinflammation in MS (Serafini et al. 2008). Previous studies have suggested that TRAIL may be a possible biomarker for neurocognitive impairment and depression (Tisato et al. 2016). TNF- $\alpha$ has a role in the inflammatory process and increased TNF- $\alpha$ levels are associated with impairment in executive functions of psychiatric disorders (Barbosa et al. 2012). Cognitive impairment and loss of functionality are more severe in bipolar disorder compared to MDD (Borkowska \& Rybakowskib 2001). We claimed that there might be a difference in terms of TRAIL levels between MDD and BD.

In the current study, no difference was determined between the BD, MDD and $\mathrm{HC}$ groups in respect of the levels of TRAIL, which participates in tumor suppression and immune cell homeostasis (Yaylaci et al. 2015). A previous study which evaluated TRAIL levels in bipolar disorder showed no difference between bipolar disorder and a control group in terms of TRAIL (10). Another study evaluating TRAIL levels in $\mathrm{BD}$ found no difference between bipolar disorder (both mania and depression groups) and the control group, and the TRAIL level was not found to be affected by a variety of mood stabilizer drugs (Yirun et al. 2017). TRAIL was reported to have a positive correlation with TWEAK, and the TWEAK and TRAIL levels were associated with the severity of mood symptoms (Yaylaci et al. 2015). In the current study, no correlation was determined between TWEAK and TRAIL. 


\section{Limitations}

There were some limitations to this study, primarily the cross-sectional design. A longitudinal study would enable a better understanding of the inflammation process in depression. Another limitation was that some confounders had to be excluded, such as dietary habits, smoking, exercise, and alcohol consumption. The most important limitation was that the patient group was using antipsychotic, antidepressant and/or mood stabilizer drugs. TNF-alpha was not measured in the study, but the CRP level was measured, and no difference was found between the three groups.

\section{CONCLUSION}

To the best of our knowledge this study is the first to have investigated levels of TWEAK and TRAIL in BD. The results showed that TWEAK levels were increased in $\mathrm{BD}$ compared to the $\mathrm{HC}$ group and there were no statistically significant differences between the $\mathrm{BD}$ and HC groups in terms of TRAIL levels. These results might contribute to the previous study which suggested that TNF- $\alpha$ antagonists could be beneficial in depression (Guloksuz et al. 2013). Nevertheless, further studies are needed, which should include unmedicated patients to provide more definitive results.

\section{Acknowledgements: None.}

\section{Conflict of interest: None to declare.}

\section{Contribution of individual authors:}

Hasan Karadağ: study design, first draft, approval of the final version.

Görkem Saygili: first draft, approval of the final version, statistical analysis.

Rabia Yüksel: study design, data collection, the first draft.

Mirac Baris Usta: first draft, approval of the final version, statistical analysis.

Canan Topçuoğlu: study design, data collection, biochemical analysis.

Gamze Erzin: study design, first draft, approval of the final version.

\section{References}

6. Akdemir A, Örsel S, Dă̆ İ, Türkçapar H, İscan N, Özbay H. Hamilton depresyon derecelendirme ölçeğinin geçerliliği, güvenilirliği ve klinikte kullanımı. 3P Dergisi 1996; 4:251-9

7. Bai YM, Su TP, Tsai SJ, Wen-Fei C, Li CT, Pei-Chi T et al.: Comparison of inflammatory cytokine levels among type I/type II and manic/hypomanic/euthymic/depressive states of bipolar disorder. J Affect Disord 2014; 166:187-92

8. Barbosa IG, Rocha NP, Huguet RB, Ferreira RA, Salgado $J V$, Carvalho LA et al.: Executive dysfunction in euthymic bipolar disorder patients and its association with plasma biomarkers. J Affect Disord 2012; 137:151-5

9. Barbosa IG, Vaz GN, Rocha NP, Machado-Vieira R, Ventura MRD, Huguet RB et al.: Plasma levels of tumor necrosis factor superfamily molecules are increased in bipolar disorder. Clin Psychopharm Neu 2017; 15:269-75

10. Borkowska A \& Rybakowski J: Neuropsychological frontal lobe test indicates that bipolar depressed patients are more impaired than unipolar. Bipolar Disord 2001; 3: 88-94

11. Brunoni AR, Supasitthumrong T, Teixeira AL, Vieira EL, Gattaz WF, Benseñor IM et al.: Differences in the immune-inflammatory profiles of unipolar and bipolar depression. J Affect Disord 2020; 262: 8-15

12. Campbell S, Michaelson J, Burkly L, Putterman C: The role of TWEAK/Fn14 in the pathogenesis of inflammation and systemic autoimmunity. Front Biosci 2004; 9:2273-84

13. Chicheportiche Y, Bourdon PR, Xu H, Hsu YM, Scott H, Hession $C$ et al.: TWEAK, a New Secreted Ligand in the Tumor Necrosis Factor Family That Weakly Induces Apoptosis 1997; 272:32401-10

14. Cretney E, McQualter JL, Kayagaki N, Yagita H, Bernard CC, Grewal IS et al. TNF-related apoptosis-inducing ligand (TRAIL)/Apo2L suppresses experimental autoimmune encephalomyelitis in mice. Immunol Cell Biol 2005; 83:511-9

15. Cunha AB, Andreazza AC, Gomes FA, Frey BN, Da Silveira LE, Gonçalves CA et al.: Investigation of serum high-sensitive $C$-reactive protein levels across all mood states in bipolar disorder. Eur Arch Psychiatry Clin Neurosci 2008; 258:300-4

16. Drexhage RC, Knijff EM, Padmos RC, Heul-Nieuwenhuijzen L, Beumer W, Versnel MA et al.: The mononuclear phagocyte system and its cytokine inflammatory networks in schizophrenia and bipolar disorder. Expert Rev Neurother 2010; 10:59-76

17. Falschlehner $C$, Schaefer U, Walczak H: Following TRAIL's path in the immune system. Immunology 2009; 127:145-54

18. Fusar-Poli L, Natale A, Amerio A, Cimpoesu P, Grimaldi Filioli P, Aguglia E et al.: Neutrophil Lymphocyte, Platelet-to-Lymphocyte and Monocyte-to-Lymphocyte Ratio in Bipolar Disorder. Brain Sciences 2021; 11:58-67

19. Goldstein BI, Kemp DE, Soczynska JK, McIntyre RS: Inflammation and the phenomenology, pathophysiology, comorbidity, and treatment of bipolar disorder: a systematic review of the literature. J Clin Psychiatry 2009; 70:1078-90

20. Grande I, Berk M, Birmaher B, Vieta E: Bipolar disorder. Lancet 2016; 387 (10027):1561-72

21. Guloksuz S, Wichers M, Kenis G, Russel MG, Wauters A, Verkerk R et al.: Depressive symptoms in Crohn's disease: relationship with immune activation and tryptophan availability. PLoS One, 2013; 8:1-8

22. Hamdani $N$, Tamouza $R$, Leboyer M: Immunoinflammatory markers of bipolar disorder: a review of evidence. Front Biosci (Elite Ed) 2012; 4:2170-82

23. Hamilton M: A rating scale for depression. $J$ NeuroL Neurosurg Psychiat 1960; 23:56-62

24. Hope S, Dieset I, Agartz I, Steen NE, Ueland T, Melle I et al.: Affective symptoms are associated with markers of inflammation and immune activation in bipolar disorders but not in schizophrenia. J Psychiatr Res 2011; 45:1608-16 

MAJOR DEPRESSION AND A HEALTHY CONTROL GROUP Psychiatria Danubina, 2021; Vol. 33, No. 3, pp 314-319

25. Hurley LL \& Tizabi Y: Neuroinflammation, neurodegeneration, and depression. Neurotoxicity Res 2013; 23:131-44

26. Jouan-Lanhouet S, Arshad MI, Piquet-Pellorce C, MartinChouly C, Le Moigne-Muller G, Van Herreweghe F et al.: TRAIL induces necroptosis involving RIPK1/RIPK3dependent PARP-1 activation 2012; 19:2003-14

27. Kim YK, Jung HG, Myint AM, Kim H, Park SH: Imbalance between pro-inflammatory and anti-inflammatory cytokines in bipolar disorder. J Affect Disord 2007; 104:91-5

28. Kopschina FP, Doorduin J, Klein HC, Juárez-Orozco LE, Dierckx RA, Moriguchi-Jeckel CM et al.: Antiinflammatory treatment for major depressive disorder: implications for patients with an elevated immune profile and non-responders to standard antidepressant therapy. $J$ Psychopharmacol 2017; 31:1149-65

29. Lamhamedi-Cherradi SE, Zheng S, Tisch RM, Chen YH. Critical Roles of Tumor Necrosis Factor-Related Apoptosis-Inducing Ligand in Type 1 Diabetes 2003; 52:2274-8

30. Lünemann JD, Waiczies $S$, Ehrlich $S$, Wendling U, Seeger $B$, Kamradt $T$ et al.: Death ligand TRAIL induces no apoptosis but inhibits activation of human (auto) antigenspecific T cells. J Immunol 2002; 168:4881-8

31. Maecker H, Varfolomeev E, Kischkel F, Lawrence D, LeBlanc $H$, Lee $W$ et al.: TWEAK attenuates the transition from innate to adaptive immunity. Cell 2005; 123:931-44

32. Miller AH, Maletic $V$, Raison CL: Inflammation and its discontents: the role of cytokines in the pathophysiology of major depression. Biol Psychiatry 2009; 65: 732-41

33. Muneer A: Bipolar Disorder: Role of Inflammation and the Development of Disease Biomarkers. Psychiatry Investig 2016; 13:18-33

34. Saas P, Boucraut J, Walker PR, Quiquerez AL, Billot M, Desplat-Jego $S$ et al.: TWEAK stimulation of astrocytes and the proinflammatory consequences. Glia 2000; 32:102-7
35. Schmidt FM, Koch J, Nowak C, Holdt LM, Teupser D, Hegerl $U$ et al.: Ligands and receptors of the TNF superfamily are decreased in major depression and during early antidepressant therapy. J Psychiatr Res 2019; 119: 116-21

36. Serafini B, Magliozzi R, Rosicarelli B, Reynolds $R$, Zheng TS, Aloisi F: Expression of TWEAK and its receptor Fn14 in the multiple sclerosis brain: implications for inflammatory tissue injury. J Neuropathol Exp Neurol 2008; 67:1137-48

37. Tisato $V$, Gonelli A, Voltan $R$, Secchiero P, Zauli G: Clinical perspectives of TRAIL: insights into central nervous system disorders. Cell Mol Life Sci 2016; 73:2017-27

38. Vogelzangs N, Duivis HE, Beekman AT, Kluft C, Neuteboom J, Hoogendijk $W$ et al.: Association of depressive disorders, depression characteristics and antidepressant medication with inflammation. Transl Psychiatry 2012; 2:1-9

39. Wiley SR, Winkles JA: TWEAK, a member of the TNF superfamily, is a multifunctional cytokine that binds the TweakR/Fn14 receptor. Cytokine Growth Factor Rev 2003; 14: $241-9$

40. Yaylact ET, Yüksel RN, Ünal K, Altunsoy N, Cingi $M$, Şahiner ŞY et al.: TNF-related weak inducer of apoptosis (TWEAK) levels in schizophrenia. Psychiatry Res 2015; 229:755-9

41. Yepes M: TWEAK and the Central Nervous System. Mol Neurobiol 2007; 35:255-65

42. Yirün MC, Yirün O, Ünal K, Yüksel RN, Altunsoy $N$, Yaylaci ET et al. Serum TNF-related weak inducer of apoptosis (TWEAK) and TNF-related apoptosis-inducing ligand (TRAIL) levels of patients with bipolar disorder in manic episodes, in remission and healthy controls. Psychiatry Res 2017; 257: 338-45

Correspondence:

Assoc. Prof. Hasan Karadă̆, MD, PhD

University of Health Sciences, Dışkapı Training and Research Hospital, Psychiatry Department

Irfan Bas,tug Street, Altındag, Ankara, Turkey

E-mail:karadagh@yahoo.com 